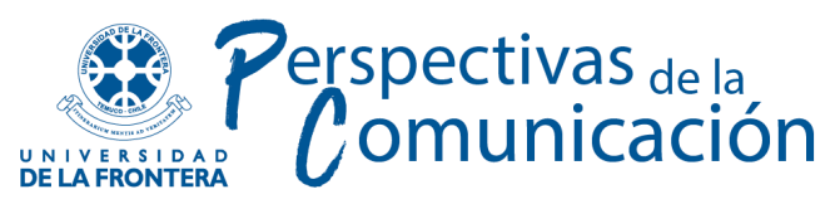

Artículo

\title{
ESPACIO PÚBLICO OPOSICIONAL Y CIBERACTIVISMO UNA LECTURA MATERIALISTA DE LA ACCIÓN CONECTIVA
}

https://doi.org/oo.00o/CoO-202O-O1

Dr. Francisco Sierra Caballero

Universidad de Sevilla, Sevilla, España

fcompoliticas@gmail.com

ORCID iD: http://orcid.org/oooo-0oo1-7398-7588

Dra. Salomé Sola-Morales

Universidad de Sevilla, Sevilla, España

ssolamorales@gmail.com

ORCID iD: http://orcid.org/oooo-0001-7085-4595

Recibido el 27 de abril de 2020

Aceptado el 8 de junio de 2020

\section{Resumen}

Internet y las redes sociales están modificando el sistema tradicional de medios de comunicación y contribuyendo a transformaciones en la esfera pública, que exigen una conceptualización más amplia del proceso de mediación social. La omnipresencia de las nuevas tecnologías de la información y la comunicación (NTIC's) en fenómenos emergentes de participación política y activismo digital ponen de manifiesto la existencia de un nuevo ecosistema informativo, que hace posible el denominado "espacio público oposicional" (Negt, 2007). Los nuevos movimientos sociales, especialmente desde 2011, han irrumpido en la arena mediática fomentando procesos de expresión y emancipación, que están resignificando los tradicionales espacios de acción colectiva, las lógicas hegemónicas y las instituciones de representación social dominante. Este artículo plantea un abordaje desde la Economía Política de la Comunicación para el estudio de las nuevas formas emergentes de 
acción colectiva, participación política y activismo digital. Además, desde una lectura materialista contribuye a la comprensión del alcance y la naturaleza tecnopolítica de los nuevos movimientos de protesta y propone una agenda de investigación acorde al contexto de crisis de acumulación que vive hoy el capitalismo, en todo el mundo.

Palabras clave: ciberactivismo, movimientos sociales, esfera pública oposicional (EPO), acción colectiva, mediación social, tecnopolítica, comunicación participativa. 


\title{
OPPOSITIONAL PUBLIC SPACE AND CYBERACTIVISM
}

\section{A MATERIALISTIC READING OF CONECTIVE ACTION}

\begin{abstract}
The Internet and social networks are modifying the traditional media system and contributing to transformations in the public sphere, which require a broader conceptualization of the social mediation process. The omnipresence of the new information and communication technologies (NTIC's) in emerging phenomena of political participation and digital activism show the existence of a new information ecosystem, which makes the so-called "oppositional public space" possible (Negt, 2007). The new social movements, especially since 2011, have broken into the media arena promoting processes of expression and emancipation, which are re-signifying the traditional spaces of collective action, hegemonic logics and institutions of dominant social representation. This article proposes an approach from the Political Economy of Communication for the study of the new emerging forms of collective action, political participation and digital activism. In addition, from a materialistic reading it contributes to the understanding of the scope and the technopolitical nature of the new protest movements and proposes a research agenda according to the context of the accumulation crisis that capitalism is experiencing today, throughout the world.
\end{abstract}

Keywords: cyberactivism, social movements, oppositional public sphere (epo), collective action, social mediation, technopolitics, participatory communication. 


\section{Introducción}

Mediactivismo, tecnopolítica, activismo digital, movimientos en red o ciberactivismo son algunos de los nombres recurrentes para designar las formas emergentes de socialización y acción colectiva que tienen lugar en procesos como Occupy Wall Street, el Nuit Debout, en Francia, el 15M, en España, el \#YoSoy132, en Mexico, o la Revolución Pingüina, en Chile. La diversidad terminológica expresa la novedad del problema que ha de abordar la Comunicología y otras Ciencias Sociales en diálogo. Desde la perspectiva epistemológica planteada en este ensayo, todo objeto de conocimiento es políticamente atravesado por la construcción y mediación social (M. Martín, 1977; J. Martín, 1987).

Las agendas de investigación, así como los métodos y epistemologías de base que configuran el saber sobre la sociedad y la naturaleza, vienen por lo general condicionadas por la conciencia posible y el desarrollo histórico de las fuerzas productivas. Si bien, en algunas circunstancias, este condicionamiento es relativo, tal y como se observa, por ejemplo, en la Comunicología. De hecho, pese a vivir en la era de las multitudes conectadas, los estudios sobre comunicación, autogestión y participación ciudadana, son más bien escasos y dispersos.

La adversa política científica de financiación de estudios orientados a una visión crítica, social y humanística del uso y apropiación social de las redes digitales, sobre el nuevo imaginario de la cibercultura, podría decirse, es, desde el punto de su impacto de los procesos de empoderamiento, irrelevante, al marcar una agenda paradójicamente improductiva o, cuando menos, de pobre imaginación sociológica.

Pero existe una memoria de las prácticas y una teoría e investigación sensible a estas experiencias de subversión y resistencia cultural. Desde un enfoque histórico crítico cabe recordar el diálogo e innovación vividos en América Latina. A lo largo de las décadas sesenta y setenta, y aún hoy, existe un interés por esta temática entre culturas y tradiciones diversas que partieron de la idea revolucionaria de que los medios median una praxis constitutiva de las culturas populares (J. Martín, 1987). También en el ámbito europeo se ha dado importancia a la guerrilla de comunicación de las radios libres o el activismo de colectivos como la Internacional Situacionista.

La inspiración de las nuevas miradas y del saber-hacer productivo en la frontera del conocimiento, del uso y la apropiación de las nuevas tecnologías que alentaron estos y otros 
proyectos pioneros de investigación en comunicación, ilustran la importancia del desarrollo de formas comunitarias y democráticas, en tanto dispositivos de representación cultural, en procesos más amplios de resistencia y lucha por la emancipación social de las clases subalternas.

La historia de la comunicación participativa, pero también las lecturas heterodoxas y creativas que procuraron transitar, por ejemplo, desde el marxismo, otros caminos y derroteros -negados por omisión o voluntad de poder de la comunicación como dominio, como diría Ramón Reig- han de ser, necesariamente, un punto de partida para analizar nuevos fenómenos como el ciberactivismo. Pero este no ha sido el criterio habitual, quizás por olvido de la historia y las continuidades que en todo proceso de mediación social tienen lugar. Así, en la literatura especializada en la materia se observa una brecha de conocimiento y omisión sobre la génesis de las prácticas autónomas de articulación de voces con fines emancipatorios que el movimiento obrero y otras experiencias innovadoras del marxismo y sus organizaciones han venido desplegando como abertura contrahegemónica desde una crítica antagonista basada en la organización, la unidad y el empoderamiento grupal y colectivo.

La lectura aquí propuesta es marxista, entendiendo el marxismo como un campo teórico fecundo para ilustrar la acción colectiva antagonista del ciberactivismo como praxis emancipadora y proceso de transformación.

De acuerdo con Jacques Rancière (2010), las nuevas formas de protesta son interrupciones en la lógica de acumulación, en los dispositivos y procesos de dominio de los aparatos gubernamentales y de normalización, al alterar la acción, lo decible, pensable y visible. Es más, si para el marxismo, como ha sugerido Massimo Modonesi (2016), la acción política desde abajo como vector de la politización de las clases subalternas es acción antagonista en estricto sentido, "lo que tratamos de esbozar aquí son elementos de una teoría marxista de la acción antagonista en la que el adjetivo antagonista implica el reconocimiento de una característica o cualidad específica de la acción política” (Modonesi, 2016: 12).

En el presente ensayo, se va a formular una primera aproximación materialista para interpretar las nuevas formas de acción colectiva en torno al concepto de "esfera pública oposicional" (en adelante EPO), de Oskar Negt (2007). A tal fin, se definen a continuación los elementos distintivos de participación y autonomía de la cultura digital en las formas 
contemporáneas de activismo digital, al tiempo que se apuntan algunos rasgos distintivos de las formas de participación y organización social que justificarían la pertinencia de esta lectura materialista a fines de comprender y dar sentido, desde una perspectiva relacional y sociocrítica, a las formas de acción colectiva en la tecnopolítica postfordista. Baste indicar que la tecnopolítica es propuesta aquí como una forma de apropiación de la tecnología por parte de la ciudadanía, un "uso táctico y estratégico de herramientas digitales para la organización, comunicación y acción colectiva” (Toret, 2013: 3).

\section{Ciberactivismo y comunicación participativa}

Toda referencia a la comunicación participativa siempre fue tipificada científicamente por razones de discurso (ideológicamente), y a nivel formal, como un proceso autónomo de proyección de las mediaciones posibles y necesarias socialmente en función de la praxis de las clases subalternas. La mirada que ha prevalecido ha sido, sin embargo, la representacional, la del contenido o ideología de la mediación y, en menor medida, la lógica o estructura, pese a su importancia. Prevalece, en otras palabras, en el análisis de las experiencias de innovación social participativa, una mirada circunscrita estrechamente a un concepto o imaginario informacional de los procesos de construcción de lo público.

Así, el concepto de "autogestión" ha sido reducido y deformado por parte del Estado y del Capital en función de una concepción normativa de la cooperación social domesticada, concibiendo la praxis de los sujetos envueltos en tal dinámica como un simple proceso de participación delegada por la que unos pocos deciden y otros participan, episódicamente claro está.

Por otra parte, el concepto de "apropiación" ha sido connotado negativamente como una práctica en contra de la propiedad, como la forma antagónica de socialización de bienes ajenos convertidos en recursos accesibles para la comunidad. Ambos sentidos comúnmente aceptados nada tienen que ver, sin embargo, con las luchas y frentes culturales de resistencia que existen, persisten y procuran alternativas democráticas a la racionalidad instrumental. Pese al dominio de una razón sedentaria incapaz en la Comunicología de proyectar otras formas posibles de producción de lo social en las mediaciones, con las viejas y nuevas tecnologías, las experiencias de apropiación y autogestión social siguen difundiéndose frente a las brechas cognitivas, a modo de grietas o líneas de fuga contra el capitalismo liberal. Ahora bien, en la era de la Autocomunicación de Masas parece lógico revisar críticamente, hasta sus últimas consecuencias, la meta-investigación en comunicación, la reflexividad 
dialéctica, recursiva y generativa del campo para recomponer las posiciones de observación, algo similar a lo que Slavoj Zizek describe en Visión de Paralaje (2006) sobre cambios de objeto y posiciones de observador.

En otras palabras, es necesario, de acuerdo con M.A. Tremblay (1982), una función de recomposición de la posición de observación, pero también de la mudanza de objetos. Más allá de cierta deriva conservadora en la teoría social que niega la lógica productiva de toda enunciación y manifestación cultural, incluido como es lógico el discurso científico, ante lo que podríamos calificar como nuevo idealismo culturalista, es tiempo de tratar de abordar productivamente las transformaciones en el ámbito de la comunicación desde una visión integral empezando por reconocer que, frente a la praxis teórica negacionista, convendría recordar que, en la era del trabajo inmaterial, en la era del acceso y la cibercultura, la "fábrica social” se fundamenta, más cerca o más lejos, de Marx, en un proceso de trabajo.

Por mucho que, desde los años ochenta, las grandes fábricas, los astilleros, las minas, los lugares comunes del trabajo fabril y de la clase obrera, fueran difuminándose en las pantallas de la Sociedad del Espectáculo, dando la sensación de evaporización de la mediación y la estructura de clase, por incisiva que resulte, en fin, la pérdida de referentes de los grandes medios de comunicación acentuada con las nuevas tecnologías de personalización del consumo; y por distraída que se nos antoje, en suma, nuestra percepción del nuevo contexto vital, no podemos dejar de soslayar, como enseñara Walter Benjamin, que, pese a todo, ahí siguen los barcos, las vigas, el carbón y el acero, el silicio de nuestras máquinas de interacción social y la arquitectura de las catedrales del capital. Del mismo modo, los nuevos templos del consumo iluminan nuestra era neobarroca, como diría Omar Calabrese, en la cual es necesario percibir, saber escuchar y sentir, como diría Pier Paolo Pasolini y que no es más que una exigencia de mayor reflexividad sobre la praxis del conocimiento, vital, como hemos apuntado, incluso más allá del avance de nuestro campo científico, pues afecta a las condiciones de desarrollo y eludir este compromiso histórico tiene sus consecuencias.

Tenemos por delante problemas urgentes como la inclusión digital, el pluralismo y la diversidad cultural en los medios y, más allá aún, el sentido mismo de ser ciudadano en un mundo global abierto y culturalmente con/fuso. Cómo abordar con garantías de éxito estas cuestiones apremiantes desde un enfoque transformador, democrático y dialógico; cómo construir democracia, democratizando el conocimiento comunicológico. En primer lugar, y a la pregunta insidiosa de qué hacer, antes que nada, justamente, articular nuevas miradas 
y bases epistémicas, incorporando los análisis de las experiencias de la gente común y corriente, abandonando la idea despótica de la masa manipulable y a merced de cualquiera que tenga los medios para convencerlos de una cosa u otra. Partimos para ello de una premisa:

Las formas de poder que están surgiendo en las sociedades contemporáneas se fundamentan en la capacidad de informar (dar forma), de construir realidad mediante significados (...) El conocimiento quizás no es igual a la acción, pero ya que la información resulta ser el principal recurso en que confirmar, conocer e imaginar se convierten en formas de construir el mundo (Zubero, 2004: 70).

Es más, se constata, de acuerdo con Moishe Postone:

Una constante transformación tecnológica, política y cultural (de la naturaleza de la producción, la dimensión social y técnica del trabajo, la estructura e interrelaciones de las clases y otros grupos sociales, de la naturaleza del transporte, la circulación, los modos de vida, la forma de la familia, etc.) (Postone, 2006: 31).

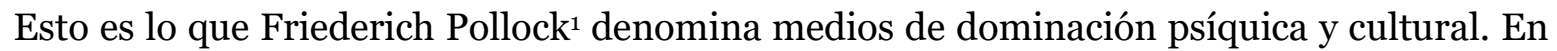
este marco, hay que situar las llamadas revoluciones 2.0, las wiki revoluciones, la praxis de los medios alternativos o el activismo digital (Mattoni y Treré, 2016). Y desde aquí, es preciso hacer una lectura otra de los procesos de transformación en marcha que incorpora la llamada revolución digital. Entre otras razones, de acuerdo con Rossana Reguillo (2017), porque han cambiado los repertorios y formas de intercambio, si consideramos por ejemplo las tecnicidades de la acción conectiva (streaming, memética, micrófono humano, hasgtag, etc.).

Las NTIC's son dispositivos de expresión de la acción colectiva que surgen como resultado de la innovación, al tiempo que articulan para los movimientos sociales, desde el punto de vista de la mediación social, nuevas condiciones de disputa de la hegemonía en la lucha por el código. De ahí la pertinencia de un estudio sociocultural de las mediaciones, aperturas y

1 Véase: (1941) "State Capitalism", en Studies in Philosophy and Social Science, 9, 220-25. Y (1941). "Is National Socialism a New Order?”, en Studies in Philosophy and Social Science, 9, 440-55. 
modelos de hibridación del espacio público que tienen lugar en las contradictorias dinámicas de articulación de la cibercultura contemporánea. Algunos problemas dilemáticos que atraviesan este campo de estudio son tradicionales en la Comunicología, pero actualizan lecturas diferentes en función del contexto. Así, por ejemplo, desde el análisis del videoactivismo (Sierra y Montero, 2016), se confrontan nuevas dialécticas y tensiones productivas en la base del proceso de movilización y acción colectiva como las que tienen lugar entre las siguientes, como se puede ver en la Imagen 1.

Fuente: Elaboración propia

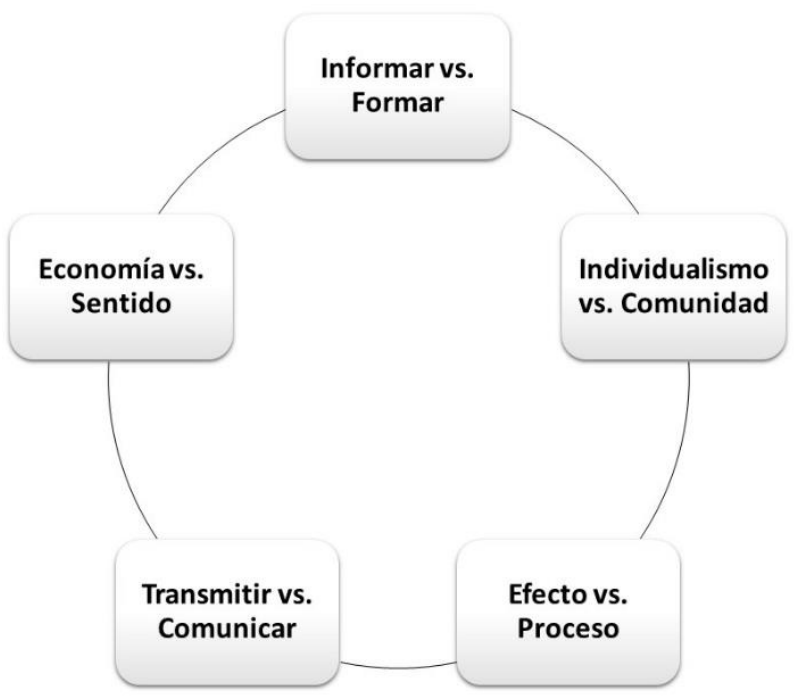

Imagen 1. Tensiones productivas en la base de la acción colectiva comunicativa

1) Informar vs. Formar: De acuerdo con la Carta sobre Derechos en Internet de la Asociación para el Progreso de las Comunicaciones APC (2006):

Internet se ha convertido en una plataforma de comunicación poderosa y popular. El acceso a Internet se ha incrementado a pesar de la constante exclusión de comunidades marginales y de miles de personas en países en vías de desarrollo. Al mismo tiempo se la vez cada vez más sujeta a la comercialización, al poder y al control corporativo. Las nuevas tecnologías de la información y comunicación, incluido el Internet, son parte del proceso de globalización - un proceso que se lleva a cabo en términos desiguales y que suelen exacerbar las desigualdades sociales y económicas entre países y dentro de los mismos. A la vez, la Internet y las tecnologías relacionales pueden convertirse en herramientas para la resistencia, la movilización social y el desarrollo cuando están en las manos de individuos y organización que trabajan por la libertad y la justicia (APC, 2006).

Perspectivas de la Comunicación - Vol. 13 - No 2 - 2020 - pp. 7-41

Universidad de la Frontera - Chile 
La cuestión de los usos depende de la pedagogía democrática que articulen estos colectivos. Del modelo distributivo a la lógica red, la máquina no separa lo social y la técnica, lo general y lo particular, sino más bien promueve "concatenaciones transversales que atraviesan múltiples planos de inmanencia permitiendo y multiplicando en éstos las conexiones" (Raunig, 2008: 98). La cuestión es observar, como anticipara Berttold Brecht ${ }^{2}$ para la radio, si Internet es un espacio de autonomía y capacitación propia de los actores políticos o simplemente un medio sofisticado de distribución de señales de acuerdo a la tradición de la teoría matemática de la comunicación y el paradigma ingenieril que ha marcado el desarrollo del sistema de telecomunicaciones.

2) Individualismo vs. Comunidad: Una de las principales observaciones que se documenta en los estudios de campo sobre el ciberactivismo es la ausencia de conocimiento empírico sobre la apropiación de las NTIC's a nivel colectivo. La prevalencia de un enfoque metodológicamente individualista ha favorecido los análisis y sistematización teórica en torno a la relación individuo-individuo con la tecnología y al impacto de los nuevos en el entorno social de acuerdo al célebre paradigma de los efectos (Sierra, 1999). Por ello, conviene ser consciente de esta dualidad tratando de modificar las visiones sobre las competencias subjetivas y las potencialidades liberadoras de las nuevas tecnologías desde las necesidades radicales de toda comunidad y un abordaje integral y consistentemente materialista. Desde este punto de vista histórico, podemos definir la comunicación popular como una forma simétrica de interacción capaz de transformar productivamente el mundo inmediato del ser como ser genérico consciente de sus condiciones materiales y protagonista de su desarrollo sociocultural. En otras palabras, la construcción de redes solidarias de articulación, esto es, la superación del narcisismo individualista en la cibercultura ha de enfrentar la lógica metodológicamente individualista de la globalización capitalista y su extensión tecnológica tanto en la práctica como teóricamente. Sólo así es posible hablar de la emergencia de un nuevo sujeto o actor-red. En otras palabras,

\footnotetext{
2 Véase: Berttold Bretch (2003). “Teorías de la radio (1927-1932)", Eptic, Revista de Economía Política de las Tecnologías de la Información y Comunicación, 5(2), 5-16. Y César Bolaño (2003). "Radio, TV, internet. Impressoes sobre as Teorías do Radio de Brecht”, Eptic, Revista de Economía Política de las Tecnologías de la Información y Comunicación, vol. 5(2), $17-21$.
} 
la transformación de la subjetividad de los procesos identitarios por el desplazamiento de los referentes culturales, corporales, espacio-temporales, geográficos y políticos, en un ágora electrónica, de despersonalización para algunos, de exacerbación del yo, o de una subjetividad compartida para otros, es un asunto que requiere de nuestra atención. El cruce de normativas que opera en la red está configurando un nuevo espacio para la construcción del o y del otro y en consecuencia para prensar la ciudadanía (Rueda, 2006: 29).

Participamos de la idea que en este nuevo marco lógico la transformación de los vínculos sociales en el ciberespacio anticipa una nueva forma de ciudadanía. Los nuevos movimientos sociales, el voluntariado y las ONGs asumen, en la práctica, un rol protagónico en las redes electrónicas y telecentros en la medida que toda máquina "es una concatenación no sólo de tecnología y saber, sino también de órganos sociales, llegando al extremo de ejercer una coordinación de los trabajadores y las trabajadoras individuales" (Raunig, 2008: 28). Cabe en esta línea, en consecuencia, problematizar la subjetividad, más allá de la visión dominante del individuo, para repensar las formas de socialidad y sociedad que se vislumbran en el nuevo ecosistema cultural.

3) Efecto vs. Proceso: La lógica de proceso, en el marco del paradigma de la mediación, piensa la comunicación desde la realidad adaptándose al nivel de comunicación correspondiente:

No podemos permanecer siempre en el nivel de comunicación oral cuando lo que las personas necesitan está a otro nivel. No podemos tampoco exigir a las personas que nos expliciten sus problemas en el único lenguaje que parece que conocemos: el oral, el del discurso lineal (Hernández, Martín y Villasante, 2002: 28).

Los modelos informacionales, lineales o extensionistas, centrados en los efectos y la racionalidad instrumental, tan habitual en los movimientos sociales y las ONGs, reeditan en este sentido el determinismo y reduccionismo tecnológico dominante en forma de simulación del cambio social. Como explicara Edward Palmer Thompson, "cuando los pueblos buscan legitimaciones para la protesta, a menudo recurren de nuevo a las reglas paternalistas de una sociedad más autoritaria y entre ellas escogen las partes más adecuadas para defender sus intereses presentes" (Thompson, 1995: 22). Así,

el e-government (o gobierno electrónico) y las redes electrónicas comunitarias parecen ubicarse en los extremos de la tensión existente entre dos tendencias. En la primera de las prácticas, se enfatiza la

Perspectivas de la Comunicación - Vol. 13 - No 2 - 2020 - pp. 7-41

Universidad de la Frontera - Chile 
profusión de canales de comunicación entre el gobierno y los ciudadanos bajo la impronta de la eficacia y eficiencia de la gestión estatal. Se fortalece la visión del ciudadano en tanto beneficiario y consumidor de servicios públicos. En la segunda, los canales de comunicación entre ciudadanos y gobierno están orientados a fomentar la deliberación pública como fundamento de la participación política, y a maximizar las posibilidades de satisfacción de las demandas. O sea que, mientras la primera tiende a racionalizar la política, esto es, llevarla al terreno de la sociedad civil, asimilándole al mercado, la segunda tiende a politizar a la sociedad, recuperando el sentido de la acción (Rueda, 2006: 28).

En este proceso, es posible observar una particular dialéctica de la autogestión y de la centralización en todas sus manifestaciones: espontaneidad/ organización; actualidad/ sentido; separación/ unión; autogestión/ heterodeterminación, expropiación/ apropiación, integración/ antagonismo que viene al caso considerar problemáticamente para un análisis de los procesos de articulación social emergentes con el ciberactivismo.

4) Transmitir vs. Comunicar: Todo medio es un interfaz, un clima o entorno. Etimológicamente, machina en latín es medio, creación, dispositivo, tanto material como inmaterial.

El término mantiene el significado técnico de aparato, marco, dispositivo, así como el significado psicológico de truco, artificio, engaño (...) La innovación técnica y la invención se fundan siguiendo las dos líneas de significado que surgen simultáneamente del término máquina (Raunig, 2008: 40).

De ahí que toda maquinación, convengámoslo, sea una maquinaria, una intentio, una forma narrativa. Ahora bien, el dominio del paradigma informacional ha tendido a ignorar esta dimensión constitutiva, favoreciendo el logocentrismo y las visiones descorporizadas de la comunicación. Sabemos que nuestro tiempo se define por la compleja concatenación de dispositivos técnicos y máquinas sociales, o, en línea con Gilles Deleuze y Felix Guattari, la construcción de técnica y objetos y la mediación entre producción y público.

La visión matricial en red implica, en esta línea, mayor flexibilidad, interconexión, horizontalidad y cercanía. Por definición, la comunicación es compleja. Es del orden de la trama y la relación. Ello exige que pensemos más en términos de comunicación y menos en procesos de información. La comunicación es entendida aquí en el marco del paradigma de la mediación. En el sentido de Raymond Williams, como estructura de sentimiento y como experiencia. Comunicación como campo de intermediación entre las determinaciones objetivas y la voluntad de cambio de todo sujeto o conjunto humano, como diría Bolívar 
Echeverría, como una fuerza transformadora. Por ello, cuando hablamos de ciberactivismo no es lo mismo pensar en términos de transmisión y red distribuida de información que en términos de comunalidad.

5) Economía vs. Sentido: El homo faber de la cibercultura contemporánea ha de enfrentarse a la lógica de la techné. Las limitaciones técnicas determinan los márgenes de la creatividad del homo ludens así como el alcance social de las propuestas de apropiación que pone en competencia la lógica de mercado. Los dispositivos técnico-funcionales constituyen pues, en este sentido, el eje de la dominación sin ideología. De Edward Shills a Fukuyama, de Raymond Aron a Daniel Bell, pasando por Seymur M. Lipset, Chaim I. Wayman y el discurso de la dominación sin ideologías, con la emergencia de la llamada sociedad postindustrial o en red, los discursos recurrentes de la tecnocracia imponen el principio de universal equivalencia al amparo del cambio tecnológico.

Una ingenua fe en los Big Data elimina (de este modo) los espacios que han sido previamente abiertos a la deliberación pública (...) mientras produce ciudadanos que, atrapados en los interminables ciclos de retroalimentación de los sistemas burocráticos modernos, entregan el proceso político a los tecnócratas, a los que siempre les gusta intervenir en retoques cuando se trata de cambios de mínimo calado en el sistema, pero raras veces se interesan por los de gran calado (Morozov, 2014).

Antonio Negri y Michael Hardt (2000) distinguen, en esta línea, tres tipos de luchas en torno a la nueva Economía Política de signos y espacios: a) el éxodo-separación; b) la producción de subjetividad fruto de la articulación de la resistencia y la afirmación de la identidad y c) la movilidad, migración, mestizaje e hibridación proliferante. Desde este punto de vista, las redes sociales, las diversas formas de cooperación y la comunicación cooperante de los mismos que impulsa la política pública, es la que intensifica el trabajo inmaterial y valoriza en este nuevo capitalismo postfordista la llamada economía creativa. De hecho, el proceso de desclasamiento corre paralelo a la mitificación sociotécnica de las NTIC's como motor de cambio y progreso social. En este escenario, y

a primera vista, no pareciera que enfoques o conceptos marxistas estén a la orden del día en los ejercicios analíticos que sobre estos movimientos se están dando; en cambio se observa en dichos análisis la persistente influencia de las mismas perspectivas teóricas dominantes desde los años ochenta, con el simple agregado temático de las redes sociales, lo cual sin duda fomenta la producción de novedades teórico-metodológicas circunscritas al ámbito de esta problemática, que por lo demás tiende a ser sobredimensionada y, por lo mismo, a correr el riesgo de provocar o acentuar un ulterior conocimiento

Perspectivas de la Comunicación - Vol. 13 - No 2 - 2020 - pp. 7-41

Universidad de la Frontera - Chile 
explicativo hacia la forma de los movimientos sociales en detrimento de su contenido (Modonesi, 2016: 19 y 20).

Contrariamente a este tipo de lecturas, hoy dominantes en la literatura especializada en la materia, en la presente propuesta partimos de la idea compartida por numerosos teóricos sociales que hoy vivimos un momento de apertura histórica marcada por la incertidumbre y la aceleración del cambio social que requiere de marcos teóricos y un aparataje categorial robusto y consistente. En este marco, la propuesta de Oskar Negt a propósito de la noción de Espacio Público Oposicional, constituye una alternativa teórica desde la subalternidad y los espacios públicos proletarios que nos puede ayudar a comprender los nuevos movimientos de activismo digital desde la autonomía de lo social y la política. A continuación, presentamos algunos elementos fundamentales a tales fines.

\section{Una lectura marxista}

La necesidad de un abordaje económico-político3 ${ }^{3}$ de las nuevas formas emergentes de participación y activismo digital en las redes sociales parte de la pertinencia de una contextualización histórica que explique procesos locales, cuyas formas de expresión y procesos de movilización colectiva, suelen ser similares, con independencia del ámbito o entorno de proximidad. Esto es, no se pueden entender procesos de crisis y contradicciones latentes que afloran en los nuevos movimientos urbanos sin ligar o correlacionar procesos, formas y dinámicas antagonistas que aparecen en lo local como resultado de la lógica general de despliegue del tardocapitalismo y su proceso de acumulación por desposesión.

La interpretación recurrente tiende, sin embargo, a incidir en la versión propia del determinismo tecnológico. La racionalidad instrumental explica así los nuevos movimientos urbanos como resultado de la expansión de las redes digitales. No hay un análisis

\footnotetext{
${ }^{3}$ La gran escuela del pensamiento económico de América Latina, la Comisión Económica para América Latina y el Caribe (CEPAL), contó entre sus miembros a Raúl Prebish, Aníbal Pinto, Oswaldo Sunkel, Celso Furtado y Maria da Conceicao Tavares, por citar a los más relevantes. Si bien la problemática central de la escuela era la del desarrollo y su gran contribución fue la formulación del conocido modelo de sustitución de importaciones, que explica y apoya la industrialización de América Latina en el período llamado "desarrollismo”, no deben subestimarse sus diagnósticos en torno a la condición periférica de la región que contribuyeron a captar, desde una matizada crítica al imperialismo cultural, la compleja lógica de constitución del espacio público y las formas colectivas de identificación en los países latinoamericanos.
} 
comunicacional en términos de frentes culturales y luchas de clases. Así, no obstante, conceptos clave de la teoría marxista como la complejidad, la totalidad, la interacción y la distinción, entre otros, como alienación y antagonismo, son claves para comprender los nuevos procesos emergentes de ciberactivismo en la medida que tratan de pensar la articulación y regulación social del plano económico al político, y de la esfera o espacio público al ámbito productivo.

La crítica de la Economía Política, como critica de la ideología, define un campo de análisis central para comprender el proceso de reproducción social ampliada en la era Internet, desde este punto de vista. Más que nada porque no es posible pensar la tecnopolítica sin una crítica del espíritu del Capitalismo Cognitivo. Esta lectura marxiana se justifica por la naturaleza de los nuevos movimientos de protesta, originados en su mayoría por la precariedad de los jóvenes urbanos, con condiciones salariales a la baja, escasas prestaciones, exclusión de la esfera pública y, en algunos casos, en situaciones de franca vulnerabilidad por la violencia y la muerte que cerca el proceso de acumulación por desposesión. El Informe "World Protest 2006-2013" (2013) demuestra que la mayoría de movilizaciones del actual ciclo de protestas responde a razones o causas estructurales de naturaleza económico-política. Así, desde el inicio de la crisis capitalista el 2008 hasta nuestros días las movilizaciones, más de 840, en 84 países se han concentrado en los países económicamente más avanzados por razones de justicia económica, pobreza y desigualdad (488 protestas), crisis de representación (376), justicia global (311) y defensa de los Derechos Humanos (302).

La lógica del capital es hoy la de la organización técnica de la producción en red. La web, entendida como consecuencia, se ha convertido en un producto configurado por las matrices y dispositivos de valorización del capital. Por ello, hablar de ciberactivismo no es pensar la tecnopolítica desde lo social, sin más, sino más bien, por el contrario, comprender las mediaciones de la tecnología desde lo político, el diseño e interfaz de lo digital como un problema de construcción social, de mediación, dialécticamente hablando. Bien es cierto que, en Marx, y este fue el aporte de la Escuela de Frankfurt, no hay desarrollada una teoría de la mediación social que explique, conceptualmente, el dominio de la comunicación, y el control del espacio público, en la base de la oposición entre crítica de la economía política y la lucha de clases y los conflictos políticos y normativos que hoy percibimos como resultado de este despliegue y colonización de los mundos de vida. De tal carencia ya hemos hablado ampliamente en otro trabajo (Sierra, 2018). Ahora, desde una lectura de la autonomía de los 
nuevos movimientos urbanos, se puede analizar críticamente el ciberactivismo a partir de conceptos nucleares como el principio de conexión, la articulación, la hegemonía, la subjetivación política y la acción social mediada, consustanciales a la voluntad de autodeterminación que resultan mucho más productivas para ilustrar los cambios que se vislumbran en nuestras sociedades (Modonesi, 2016). Una de estas lecturas, aquí apuntadas, es la que nos aporta Oskar Negt y Alexandre Kluge.

La pertinencia del concepto que introducen ambos autores de Espacio Público Oposicional (EPO) se justifica por la naturaleza de los nuevos movimientos urbanos, que procuran irrumpir en el cerco mediático en la búsqueda de expresiones públicas más allá de las instituciones de representación social dominante. En "Historie et subjectivité rebelle", Negt y Kluge reformulan de modo heterodoxo el núcleo conceptual del marxismo dando forma al sentido de espacio público proletario opuesto al sistema dominante de mediación, lo que nos lleva a problematizar las representaciones en las contradictorias y complejas dinámicas de la ambivalente lógica de la reproducción social, en el plano material y, desde luego, en el campo de lo simbólico.

A partir del análisis sobre qué tipo de espacio, qué formas de interacción e intercambio tienen lugar en el dominio público y qué función mediadora tienen tanto los medios convencionales de información como hoy las redes sociales, la pertinencia de este marco teórico de referencia para pensar el ciberactivismo en tales términos, se antoja del todo pertinente desde el punto de vista de la relevancia de las preguntas y abordajes aportados como en la distinción de las formas disímiles de organización de la mediación social conforme a la dinámica y estructuración de la reproducción de la sociedad de clases.

Si consideramos la constatación de experiencias de largo recorrido como el 15M en España o el movimiento Occupy Wall Street, observamos que ambas formas de acción colectiva tienen en común que implicaron una alteración radical de las condiciones de enunciación y representación del espacio público, tanto en el plano virtual como en el físico. La problematización de la relación entre espacio público (físico) y esfera pública (plano virtual, simbólico) está en la base del objeto de discusión de la tradición materialista desde Marx. Toda tecnología como producto cultural es fruto de una mediación objetivadora y una voluntad subjetiva. Esta articulación interna no es escindible, salvo analíticamente. Desde una lectura estructural, y considerando el contexto histórico, como Marx explicara a propósito del fetichismo de la mercancía, la lógica de valorización es la causa explicativa que 
ilustra la tendencial proyección o imagen ilusoria (por ejemplo, el clickactivismo), como dinámica objetiva de realización.

La lógica mercantil, en otras palabras, opera en el plano subjetivo y en la forma material de reproducción. Por lo mismo, la antagónica lectura de lo real y lo virtual, como realidades desconectadas, no es sostenible. Bien es cierto que, como recuerdan Elena Grau y Pedro Ibarra,

las manifestaciones en la calle son acciones radicalmente tradicionales. Asumen uno de los rasgos característicos -e históricamente constantes- de una de las formas clásicas de la acción colectiva: los movimientos sociales. Porque las manifestaciones no sólo tienen una virtualidad instrumental o identitaria, sino cuasi constitutiva de los movimientos sociales (Grau e Ibarra, 2004: 7).

En esta línea, el ciberactivismo conecta con la necesidad de expresión y con los procesos identitarios que se dan en el seno de los nuevos movimientos urbanos. Ahora bien, todo movimiento social se proyecta en el espacio público al definir su diferencia y hacer visible su vindicación, indistintamente en la calle o en la red. La frontera entre lo virtual y lo real es un reto, en fin, de producción de la ciudadanía en la crisis de representación y desafiliación que vive la democracia formal representativa (Castel, 2006). Aquellas teorías que idealizan la necesaria doble articulación de forma separada terminan por sobredimensionar la autonomía de la comunicación o el lenguaje. Es el caso de la Teoría de la acción comunicativa de Habermas. Por ello, las tesis del EPO empiezan por formular una crítica de la esfera pública burguesa y la idea kantiana de república de los sabios, que implica otra lectura radicalmente distinta del intercambio y el proceso comunicacional.

Frente al idealismo comunicacional, Negt destaca las formas de deliberación, reconocimiento y antagonismo de las clases dominadas:

La conscience collective, qui est le produit d'une coexistance entre les structures identitaires du moi, des déchirures du moi (éclats) et de la nation (ou plutôt de sa decomposition et de son carectère inachevé), s'affirme a travers deux processus distincts et antagoniques, par une face représentative et une face prolétarienne. Ce type de processus ne peut produire qu' une fausse conscience (Negt, 2007: 21).

Por espacio público proletario cabe definir aquel dominio público en cuyo seno los sujetos dan forma, como sujetos de la infrapolítica, a su expresión, intereses y aspiraciones 
existenciales. Comprende el conjunto de dimensiones sociales, experiencias, formas y características esenciales que son específicas de los grupos oprimidos (Negt, 2007: 38). Desde este punto de vista, no es posible separar vida material y significado, menos aún para una crítica de la mediación social. Igualmente, como advierte Étienne Balibar, cabe formular una crítica de ciertas lecturas marxistas dominantes al interpretar los procesos de representación que han privilegiado una concepción abstracta y formal de la ciudadanía (Balibar, 2004). Así, la imagen e imaginario del espacio público tiende a presentársenos como algo fijo y estático cuando sabemos, desde una perspectiva histórica, que las instituciones y formación del dominio público varían a lo largo del tiempo y en diferentes sociedades.

El espacio público es tanto lugar como proceso de apropiación social con la que organizamos nuestra experiencia del mundo. La mediación, desde este punto de vista, es el proceso por el cual la estructura pulsional, la conciencia y el mundo exterior entran en contacto. De hecho, el videoactivismo, por ejemplo, es básicamente una praxis del pathos, de la conmoción, de la emoción compartida por la acción y el movimiento social, de modo que el acontecer, que por definición es ingobernable, rompe así con la comunicación como dominio en la administración de las emociones inducidas por la industria cultural. En este sentido, en el paso del plano informacional (o del paradigma de la representación) a la dimensión expresiva, el giro de las emociones en la interpretación de las nuevas formas de protesta y acción colectiva justifican esta mirada, en el sentido de que sin el estudio de las emociones no es posible comprender los procesos de comunicación humana. Y para ello el enfoque marxista de tradiciones heterodoxas como las que aquí se apuntan dotan a la teoría crítica de herramientas para la comprensión cabal de los procesos en curso a lo largo y ancho del mundo, comenzando por trascender la tradición positivista de la escuela crítica. En esta línea, las tesis de EPO parten de la voluntad de superación de una concepción limitada del dominio y opinión pública.

En su principal ensayo sobre el EPO, Negt critica a Habermas por su idealización teórica del proceso dialógico que enuncia en su Teoría de la acción comunicativa ante realidades comunes como la violencia simbólica y las asimetrías que recorren el espacio público real y concreto.

Habermas introduce en los estudios de comunicación política tres temas caros a la tradición marxista: la regulación y control social de la mediación cognitiva; la transmisión de 
información y el conocimiento como un problema axiológico; y la dialéctica de subsunción y dominio de la esfera pública concebida como opinión pública privatizada. A partir de conceptos como producción, circulación e ideología, el filósofo alemán ilustra la evolución histórica de la comunicación política y su captura por la clase dominante más allá de visiones sistémicas o descarnadas, materialmente, como las que las ofrecidas por Niklas Luhmann.

El problema de la historia y la crítica de la opinión pública propuestas por Habermas es que parte de un falso dualismo entre producción social e interacción comunicativa, entre trabajo y vida. Un dualismo insostenible, si tomamos en serio el discurso crítico de Marx, como ilustra Bolívar Echeverría (1994). Es más, de acuerdo con Lothar Bisky,

el dualismo que Habermas tiene presente sólo se consigue ocultando estas relaciones de producción. Con este ocultamiento queda libre el camino para relacionar únicamente el trabajo (acción instrumental) con el desarrollo del hombre como ser natural y la interacción (acción comunicativa) únicamente con el desarrollo del hombre como ser social, con el proceso social; ahora bien, con un proceso social del que están excluidos la economía y, sobre todo, las relaciones de producción (Bisky, 1982: 105).

La caja negra, en suma, del concepto de esfera pública en Habermas es una racionalización que termina por anular, de forma idealista, las contradicciones que recorren todo intercambio simbólico o proceso de mediación. Al grado que, la propuesta de condiciones de racionalización del diálogo en las formas de comunicación y deliberación ciudadana no se dan, entre otras razones, pese al marco teórico que formula porque la comunicación está dominada por relaciones de producción y una estructura de control irracional. La liberación de las coacciones institucionales propias de la administración comunicativa termina siendo, de este modo, un mero deseo ajeno a las condiciones materiales del mundo del trabajo y la lógica de la reproducción capitalista.

Los universales pragmáticos de las condiciones de habla poco pueden hacer ante los dispositivos y lógicas de enunciación que derivan de la subalternidad y estructuración de la lógica de clases. Es más como indica Bisky:

El procedimiento de Habermas es interesante: abstrae de grado en grado hasta que cree haber hallado los universales que constituyen la base de todos los actos discursivos. Pero faltan (porque hizo abstracción de ellos) los sujetos que realizan estos universales. Sencillamente se suponen (Bisky, 1982: 108). 
En este sentido, prevalece una concepción pragmática, lingüística y descarnada. De modo, que la validez intersubjetiva de las normas y su aplicación, trascienden a los sujetos, su historia y posición social. La praxis queda relegada por una concepción de la "verdad" que, so pretexto de superar las limitaciones de Marx al respecto, termina transitando del positivismo y la determinación a la idealización del intercambio y de la comunicación. La inconsecuencia práctica, como apunta Bisky, es una práctica común del idealismo comunicacional, del "pancomunicacionismo" y la idea de comunicación sin dominio hoy en boga con las nociones de la neutralidad de Internet y la llamada auto-comunicación de masas. La revisión de Marx planteada por Habermas:

\footnotetext{
se dirige contra el carácter material de las relaciones de producción existentes: calla que los sujetos capaces de hablar y de actuar encuentran determinadas relaciones de propiedad, relaciones de clase, etc., que no solo determinan el marco institucional de la distribución, sino también el desarrollo de estos sujetos capaces de hablar y de actuar. Con la validez intersubjetiva de la norma, Habermas se refiere evidentemente a la relación de clase. Sin embargo, esta última sigue careciendo de problemas para él, aunque se basa, como la forma de tráfico en general, en reglas de acción comunicativa o de interacción simbólicamente mediada (Bisky, 1982: 110).
}

Desde este punto de vista, como reconocen otros referentes de la tradición crítica, ni las condiciones de validez del habla ni la racionalización de los intercambios son universales, empezando por el reconocimiento del otro, ni el giro lingüístico puede explicar procesos materiales que tienen que ver con la subjetividad, el cuerpo y el espacio particular del proletariado. A decir de Moishe Postone, "Habermas desarrolla una teoría de la lógica interna del desarrollo socio-cultural como un proceso de linguistificación de lo sagrado" poco o nada adecuada a la realidad de las multitudes conectadas (Postone, 2006: 328). La contradicción principal, en fin, atribuible a la noción de esfera pública en Jürgen Habermas, se constata entre la lógica abstracta de generalización del concepto de opinión pública y las experiencias concretas y singulares de los grupos subalternos. Se da así una lógica o lenguaje formal racionalizado frente a la dialógica del sentido común de la experiencia, del lenguaje corporal y la construcción colectiva de formas de reconocimiento en común que terminan siendo subsumidas y obliteradas en la comprensión de los procesos que tienen lugar en el capitalismo. Ahora bien, sabemos que históricamente no hay mediación social sin dialéctica de la experiencia. Ello implica explorar el plano de la inmanencia con todas sus consecuencias. Si bien Habermas formula una propuesta potencialmente emancipadora a partir de la síntesis y la interacción, la lectura evolucionista que formula de la Opinión 
Pública es del todo cuestionable. Su lectura positiva y logocéntrica de la producción, o la tecnología, sin contextualizar, limita su alcance en la comprensión del proceso de mediación social. Empezando porque es necesario reconocer que no hay lógica interna universal ni una dinámica empírica similar o equiparable al espacio público de territorios e historias culturales disímiles.

El punto de partida de la crítica de Habermas es pues universal: a pesar de ser social, en su esencia no se conforma cultural, social o históricamente, sino que se fundamenta en el carácter ontológico de la acción comunicativa a medida que se despliega a lo largo del tiempo. El lenguaje ocupa entonces un lugar en la teoría de Habermas directamente análogo al que ocupaba el trabajo en los tipos afirmativos de marxismo tradicional (Postone, 2006: 329).

El esfuerzo de la teoría de la acción comunicativa por fundamentar una nueva teoría crítica de la sociedad moderna confunde acción comunicativa con diálogo racional y, epistemológicamente, limita la crítica marxiana del dominio público por la pragmática del giro lingüístico. Ahora, cómo podemos explicar la constitución de la esfera pública sino por imposición y antagonismo. La lectura universalista, etnocéntrica, pancomunicacional, diríamos, casa mal con el desarrollo histórico real que puede colegirse de un análisis genealógico de la modernidad. Por otra parte, además, una lectura materialista y emancipadora del dominio público no puede ser dicotómica en términos de organización sintáctica. Es más,

\footnotetext{
$\mathrm{Al}$ adoptar la forma abstracta de la comunicación mediada por las mercancías como valor principal, este enfoque no permite una teoría de las ideologías seculares o un análisis de los grandes cambios en la conciencia, las normas y los valores que se han sucedido en la sociedad moderna en el curso de los últimos siglos, cambios que no pueden comprenderse simplemente en términos de oposiciones del tipo tradicional y moderno, o religioso y secular (Postone, 2006: 333).
}

Cabe formular, con Bolívar Echeverría, una crítica a la teoría de la racionalización cultural de Max Weber, de la que Habermas es partícipe, por resultar transhistórica. La asunción de esta visión en la teoría de la acción comunicativa limita el alcance, tecnocráticamente, de la crítica de la mediación social al racionalizar y comprender la modernidad postliberal en la crisis de la esfera pública por la subsunción de la llamada "administración comunicativa", sin considerar otras dimensiones y relaciones igualmente sustantivas para ilustrar el proceso de colonización de los mundos de vida. 


\section{Elementos para el análisis del EPO}

Un elemento, a nuestro juicio, nuclear en este punto es problematizar la experiencia social, el acto o proceso de significación que hace posible la reproducción social entre el sistema normativo y la vivencia del sujeto o actor político. Como teoría históricamente específica de la mediación social, el enfoque necesario contra Habermas, es una teoría de las modalidades determinadas, de acuerdo con Moishe Postone, de la conciencia y la subjetividad. Solo así es posible pensar nuevos fenómenos como la ideología de la tecnopolítica al reflexionar sobre las relaciones entre activismo, comunicación subalterna y medios convencionales.

En la misma línea, el trabajo desplegado junto con Alexander Kluge 4 es del todo relevante en la medida que sitúa el papel de la mediación en la interfaz entre subjetividad rebelde y trabajo vivo. Kluge y Negt (1993) ponen el campo de la comunicación, la experiencia mediada, a nivel sociocognitivo, y la lógica del valor, desde nuevos parámetros. Podemos definir así la alienación como aquella mediación social que segrega, que separa representación y experiencia real, en parte en virtud de varias lógicas de captura que Negt explica en su crítica del EPO. A saber:

- La apropiación de la experiencia social por nuevos espacios públicos de producción.

- La proyección del conocimiento en forma de soberanía del imaginario y un concepto ficticio de interés general.

- La captura industrial de las mediaciones cognitivas sobre lo real a escala macro desligada de lo local, próximo o concreto.

- La ruptura entre industria privada del espectáculo y dominio público o entre espacio público y monopolios privados.

- La imagen aparente de la administración comunicativa en una forma de falsa transparencia dominada por la racionalidad de la confidencia en la que el secreto es la norma.

- La reducción al dominio privado y doméstico de la experiencia de vida de la población subalterna.

- La autonomía o lógica de la universal equivalencia del libre flujo e intercambio de la información.

${ }^{4}$ Veáse: Kluge, A. (1981). “On Film and the Public Sphere”, New German Critique, nos. 24-25, 206-220. 
- La negación de la socialización primaria como fuente de conocimiento y conciencia posible de lo real.

- El bloqueo de la lógica de la emergencia de la comunicación alternativa de los espacios liminares y antagonistas de los grupos subalternos.

- La descualificación y rechazo de la experiencia proletaria y su espesor histórico como experiencia reveladora y significativa.

- La demarcación de espacios segregados de las clases subalternas.

Desde este punto de vista, la noción de EPO apela a resignificar los tradicionales espacios de proximidad tradicionales que los estudios de la denominada folkcomunicación ${ }^{5}$ abordan como formas populares de convivencia, confianza, apertura y comunidalidad hoy progresivamente colonizadas por la ocupación imperialista de los mass media y sobre todo las nuevas tecnologías. Frente a estas lógicas de la esfera pública burguesa dominante a través de los medios de las instituciones hegemónicas de mediación social, por ejemplo, la industria cultural, el EPO se caracteriza por:

- El uso proletario de los símbolos como la identificación y el sentimiento de colectividad.

- La lógica del encuentro, el contacto, el contagio y el instinto materialista de agrupamiento y conexión.

- La política de la expresión, manifestación y ocupación de los espacios públicos.

- La amistad y celebración de la solidaridad y fraternidad.

Los casos analizados por el proyecto "Ciberactivismo, ciudadanía digital y nuevos movimientos urbanos"6 validan tales hipótesis a través del análisis de diversas movilizaciones, donde se producen esferas públicas de discusión con autonomía respecto a

\footnotetext{
${ }^{5}$ El término folkcomunicación acuñado por Luiz Beltrão en su tesis doctoral titulada "Folkcomunicación - Un estudio de los Agentes y de los Medios Populares de la Información de Hechos y Expresión de Ideas", en 1967, designa el "conjunto de procedimientos de intercambio de informaciones, ideas, opiniones y actitudes de los públicos marginalizados urbanos y rurales, a través de agentes y medios directa o indirectamente ligados al folklore”. (Rabaça y Barbosa: 1987, 611). Para profundizar véase: J. Marques de Melo (2002). “Aporte brasileño a la Teoría de la Comunicación. El Estudio de la Folkcomunicación según Luiz Beltrao”. Razón y Palabra, 27. En línea: http://www.razonypalabra.org.mx/anteriores/n27/jmarques.html\#6a

${ }^{6}$ Francisco Sierra Caballero es el Investigador Principal del Proyecto Nacional de I+D "Ciberactivismo, Ciudadanía Digital y Nuevos Movimientos Urbanos” (CITYCOM), Ministerio de Economía y Competitividad, Gobierno de España (Madrid, 20162019).
} 
la estructura real de la información. Esta lógica del EPO se distingue, por tanto, por una radical ruptura con las formas o modos de producción discursiva como por las lógicas de creación o mediación social. Por ejemplo, el anonimato, la coproducción de imágenes y textos, la producción comunal de memoria, etc. En otras palabras, la autonomía presupone oposición al imaginario instituido y autonomizado. En este proceso, la emergencia de un EPO depende de tres factores concomitantes, desde un análisis estructural:
A. La articulación de los intereses subalternos.
B. El intercambio y la motivación.
C. Las tendencias destructivas propias de la desagregación de la esfera pública burguesa por efecto del proceso de acumulación y despliegue del capitalismo.

A estos factores determinantes, cabe añadir, además, la necesaria politización de la experiencia en la producción de sentido propio -como sentido común- y la capacidad de articulación de la inteligencia social general, con relación al espacio público proletario que ha de enfrentar las dinámicas destituyentes de la esfera burguesa y sus lógicas por medio de:

- El enmascaramiento de las relaciones de dominio que impone el capital.

- El imperio de la fijación institucional constitutiva del espacio público como lugar fijo del orden social.

- La representación del espacio público como forma de organización de la dictadura de la clase dominante con normas, procesos de legitimación, procedimientos, conductas, decisiones, delimitaciones y procesos de distinción claramente clasistas.

- La lógica de separación y delimitación de los sujetos, los medios de producción y los mundos de vida.

- La representación ilusoria de la totalidad social.

- La sobre-representación de valores de uso superfluos.

- La dicotomía de lo público y lo privado en términos de una relación exterior y hasta opuesta.

- La negación de la autogestión de la vida cotidiana de la clase obrera como campo de disputa y oposición.

- La disgregación y dispersión.

- La publicidad monopólica que confunde, como criticara Habermas, lo público con lo publicado.

- La fragmentación, fraccionamiento y proyección imaginaria de la necesidad de armonía e integración.

- La violencia simbólica. 
- La mixtificación, la falsedad y la manipulación.

- La formalización excluyente.

- La despolitización de la propia mediación.

De la comunicación en sí -como esencia- a la mediación social para sí -como proceso-, se propone una crítica, desde la realidad de los grupos subalternos y su praxis emancipadora. Lo cual implica, necesariamente, la confrontación de la racionalidad de los mundos de vida que acompañan a los discursos sobre el ágora virtual como nuevo renacimiento de la democracia. Desde esta perspectiva es desde donde analizamos los procesos contingentes de resistencia, ensamblaje y rearticulación social. Esto es, repensando las remediaciones de la ciudadanía digital. A partir de esta matriz o base conceptual es posible dirimir si el ciberactivismo ha dado lugar o es consecuencia de una nueva cultura política, una nueva subjetividad y forma de acción colectiva o, por el contrario, si reproduce el imaginario y la lógica institucional dominante.

Sabemos que Internet constituye una potente herramienta de solidaridad y co/implicación. A través de las comunidades virtuales se refuerzan los vínculos de pertenencia e identificación desarticuladas por el "turbocapitalismo", concepto acuñado por Edward Luttwak, que explica el proceso de globalización que corroe el tejido social y que crea mucha pobreza, además de profundas transformaciones en las relaciones laborales: precariedad, inseguridad, marginación... (Luttwak, 2000). La red de redes es, en este sentido, un espacio informal de articulación de espacios de encuentro, de reconocimiento y conciencia común en la formación de proyectos colectivos. Ahora bien, hasta qué punto la nueva oleada de movilizaciones y protestas sociales da lugar a nuevas lógicas de transformación del dominio público, qué alcance y dimensiones cabe advertir como realidades singulares en las nuevas formas de tecnopolítica y acción colectiva si consideramos el contexto histórico-social más general de transformación y desarrollo del nuevo espíritu del capitalismo. No es objeto de este artículo desglosar todos y cada uno de los problemas suscritos a propósito de la discusión propuesta. Tomando en cuenta la pertinencia y actualidad de una lectura materialista de los nuevos procesos de remediación social, y a tenor de los considerandos aquí expuestos brevemente para delinear un enfoque marxista de las nuevas formas de producción que acompañan la llamada revolución digital, vamos a limitarnos al menos a apuntar varias líneas de investigación desde este enfoque materialista que hemos tratado de defender sucintamente a propósito del ciberactivismo actual. 


\section{Conclusiones y agenda de investigación}

Hemos visto que la comunicación a través de redes sociales desarrolla nuevas prácticas, modos interpersonales de construcción de la subjetividad distintos al "reconocerse" que da lugar a nuevas formas proyectivas de los imaginarios colectivos. Las mediaciones del sentido común y de la pertenencia exigen en consecuencia otra mirada sobre el factum de lo común. Desde el punto de vista de la investigación cabe problematizar numerosas cuestiones, siempre, como hemos venido argumentando, desde una perspectiva materialista y emancipadora. La cultura digital plantea problemas de modelo de desarrollo, derechos de acceso, cuestiones de Justicia y representación, dilemas teóricos y económico-políticos, así como discusiones de calado sobre el proceso de reproducción cultural en una fase de mercantilización extrema del conjunto social. Esta dinámica impugna el modelo representacional incluso el discurso académico antagonizando con la figura del intelectual y su habitus como una suerte, en palabras de Daniel Blanchard, de confiscación personalista de la palabra y de cosificación de los sectores subalternos por efecto de una suerte de violencia simbólica que objetiva a las víctimas como sujetos silentes y pasivos (Blanchard, 2007).

Ahora, si tuviéramos que destacar, sobre numerosos aspectos susceptibles de ser abordados por la investigación social, a nuestro juicio cabe cuando menos señalar cuatro líneas prioritarias de investigación para repensar desde una lectura marxista los procesos emergentes y contrahegemónicos de comunicación en los frentes culturales que acompañan al activismo digital. A saber:

A) La apropiación tecnológica y la organización social. La tecnocultura da lugar a una multiplicidad de nuevas prácticas, formas de mediación y auto-organización social, que, con la proliferación de nuevas formas de experiencia en las redes sociales, alteran y reformulan los modelos de reproducción social de referencia en los que se observan lógicas ambivalentes de articulación. De hecho,

la cibercultura, entendida como el espacio de comunicación e interacción creado por la red Internet, genera en su interior grandes inequidades, exclusiones y ejercicios de poder y dominación a través de las redes de información, pero también abre una posibilidad a la imaginación y la creatividad social (Rueda, 2006: 20). 
A este nivel tenemos pues la cooperación solidaria, la autonomía y praxis mancomunada y la apropiación de los medios y tecnologías. La comunicación participativa debe ser observada, en este sentido, como una lógica de constitución de la multiplicidad y autonomía social. Más que el proceso de apropiación y reconfiguración de la llamada esfera pública, es preciso focalizar en las nuevas articulaciones comunitarias. En este sentido, el ciberactivismo es una suerte de recomposición y ensamblaje de la economía moral de la multitud. De acuerdo con Jodi Dean,

los nombres, las tácticas y las imágenes comunes están juntando los fragmentos, haciéndolos legibles como los numerosos frentes de una única lucha contra el capitalismo. Allí donde la proliferación de asuntos e identidades nos dispersa y debilita -propiciando el sarcasmo que glorifica su crítica incluso cuando socava la solidaridad -, los acontecimientos multitudinarios de la última década están forzando un nuevo sentido del poder colectivo. Han hecho que las expectativas de multiplicidad den paso a experiencias de colectividad (Dean, 2017: 41).

En la misma línea, el concepto de apropiación debe ser repensado como una categoría en movimiento y la investigación, a decir de Jesús Ibáñez (1994), debe abandonar la razón sedentaria para procurar una mirada nómada de las redes, espacios e intersticios de producción de lo común. No sólo la investigación social y comunicológica ha de ser, necesariamente, creativa y tomar conciencia de los efectos productivos en la realidad social. En el propio proceso de apropiación, ha de reconocer, por principio, que la gente común desarrolla la capacidad creativa de nuevos usos y significados de los objetos y/o procesos apropiados.

En esta voluntad insubordinada, las experiencias de las personas, las formas de mímesis y subversión, tanto en el proceso de apropiación como en la autogestión, no siguen una lógica unívoca, sino que más bien tienen lugar de forma diferente, según los individuos e intereses, del mismo modo que el lenguaje, como Mijaíl Bajtín demostrara, siempre es polisémico. Es más, la dinámica de las culturas populares, se asocia, en fin, a diferentes significaciones sociales, relacionadas directamente con una expansión de su uso y a una conformación de prácticas y procedimientos cotidianos que normalmente desbordan las estrategias mercadológicas o burocráticas de programación y definición a priori de la materialidad viva de lo social. Tal enfoque crítico parte de la construcción, y crítica, del mito de la modernidad sobre la ilusión o falsa transparencia de la información como propiedad del proceso de mediación. A nuestro entender, siguiendo a Ernesto Laclau y Chantal Mouffe: 
Toda relación de representación se funda en una ficción: la de la presencia a un cierto nivel de algo que, estrictamente, está ausente del mismo. Pero por el hecho mismo de que se trata a la vez de una ficción y de un principio organizado de ciertas relaciones sociales, la representación es el terreno de un juego cuyo resultado no está predeterminado desde el comienzo (Laclau y Mouffe, 2004: 161).

Considerando estos términos, la propuesta de EPO, exige explorar los modos propios de comunicación, las estéticas de resistencia, los contornos del espacio público antagonista en sus formas de expresión y autogestión empezando por analizar los patrones de participación, las estructuras organizativas, las formas de protesta y las políticas institucionales de reconocimiento y autonomía en sus manifestaciones singulares, específicas, reales y concretas.

B) Interactividad y nuevos modelos de mediación social. El nuevo ecosistema informacional plantea la necesidad de discutir en detalle los niveles y formas de pertinencia social de la interacción. Pues la interpenetración de trabajo y vida, lo público y lo privado, la producción y reproducción de lo social atraviesan en distintas lógicas de ambivalencia las nuevas formas de mediactivismo7. Ello implica discutir los procesos y metodologías, por ejemplo, de participación de la ciudadanía en espacios e instituciones como las webs municipales, así como los modelos de gobernanza y gestión de los intercambios sociales. Pues, de acuerdo con György Luckacs, no todo lo nuevo es bueno, ni toda innovación es progresiva.

La irrupción de las tecnologías de la información en la vida contemporánea debe, por lo mismo, ser cuestionada, desde el punto de vista de la reflexividad social general, en términos de Ciencia y sociedad, de modelos orgánicos o de ingeniería social, explorando las nuevas matrices culturales, el discurso público y los proyectos de desarrollo que acompañan a la configuración de las formas permitidas y negadas de mediación. Volvemos al dilema de "cómo hacer cosas con palabras", como planteara hace cinco décadas John Langshaw Austin, en su obra de 1962. "No se trata de la esencia sino del acontecimiento, lo que

\footnotetext{
${ }^{7}$ Véase: A. Fernández-Sabater (2005). “Mediactivismo, producción alternativa de imágenes, televisión. Entrevista con Franco
} Berardi”. El viejo topo, 203, 72-75. 
necesitamos saber no es el es, sino el $y$ : las concatenaciones y movimientos que constituyen una máquina” (Raunig, 2008: 24).

Cabe pensar si, como propone Jamais Cascio, las redes sociales funcionan como un "panóptico inverso", en el cual la periferia vigila al centro del sistema o, si se trata de un sistema estricto de clausura y control social expandido.

C) Memoria y gestión local del conocimiento. La nueva Alejandría, con la digitalización de los repertorios y códigos culturales, plantea nuevos retos y problemas que van más allá de los derechos de autor o la salvaguardia del patrimonio inmaterial. Proyectos como Europeana ${ }^{8}$, no conciben, por poner un caso, el reto ciudadano, el problema de política cultural que se vislumbra en la nueva cibercultura del posnacionalismo y el libre cambio neoliberal, donde el Capitalismo Cognitivo (Blondeau et al., 2004; Sierra, 2016) expropia y despoja de sus códigos culturales a las clases subalternas. Esto es, el reto de la llamada sociedad cognitiva no es de sustentabilidad financiera ni de respeto al derecho moral sobre las obras sino más bien de configuración democrática y política de las exomemorias digitales y la capacidad de autonomía y auto-determinación de las culturas populares en un escenario que, como intuía Dallas W. Smythe (1983), convierte la economía de la atención en un intensivo proceso de colonización y explotación de la experiencia y vida particular de cada sujeto. Sabemos, bien es cierto, que el discurrir del tiempo tiene un poder mediador alterativo, modifica el estatuto cultural de los sistemas de representación convirtiendo acciones significativas en mitemas ${ }^{9}$, enmarcando y dotando de sentido los objetos contingentes, y destacando el acontecer, sea trivial o relevante, como un orden mosaico de referencia. Ahora, si queremos comprender esta lógica, cabe advertir que el proceso de intervención a este nivel de la mediación social exige un camino de ida y vuelta: de la política a la técnica y de la técnica a la política. De lo contrario, como dijera E. P. Thompson (2002), nos encontramos con las vías muertas, las causas perdidas y el olvido de los propios perdedores en la Historia.

\footnotetext{
${ }^{8}$ Europeana es un portal de acceso a millones de recursos digitales de archivos, museos, bibliotecas y colecciones audiovisuales europeas. El proyecto que dió comienzo a la construcción de Europeana, se denominó European Digital Library Network (EDLnet), fundado por la Comisión Europea dentro de su programa eContentplus. En línea: https://www.europeana.eu/portal/es

${ }_{9}$ Véase: Claude Lévi-Strauss (1952). "La estructura de los mitos”, Antropología estructural. (pp. 229-252). Barcelona: Paidós.
} 
D) Economía Política del Cambio Tecnológico y la Innovación Social. La mirada sociocéntrica de las NTIC's limita las potenciales dinámicas de interacción de las herramientas en la galaxia Internet. Sólo la concepción modernizadora y administrativa permea el discurso público institucional de los actores sociales en los procesos de cambio mediados tecnológicamente. Pero ni la supuesta política de la transparencia ni la participación incorporan una forma distinta de articulación con calidad democrática. Los nuevos espacios electrónicos pueden constituir un ágora virtual, un nuevo teatro absolutamente funcional, en la práctica, a las grandes corporaciones, convertidos ahora en los sujetos y actores de los tiempos de la globalización neoliberal (Herrera, 2007: 47). La cuestión pues es ver si las redes digitales nos permiten articular espacios socialmente abiertos, innovadores y autónomos, si contribuyen a establecer reglas y procedimientos, contrapoderes y espacios de interlocución y empoderamiento o, por el contrario, replican lógicas de dominio tradicionales.

La innovación que resulta de estar en disposición de aprender es un imperativo general, un valor que afecta tanto a la organización empresarial como al modelo de convivencia que hemos de diseñar, tanto a las formas de expresión en el mundo de la cultura como a las políticas públicas (Innerarity, 2009).

Un ejemplo de ello es el de las llamadas smart cities o ciudades digitales. Emerge un nuevo tipo de urbanidad, a medio camino entre la física territorial y el imaginario tecnoutópico, tejido como un conjunto de historias, voces, ritmos y sonidos de recreación social hoy proyectados en la red como nuevo espacio y forma de interacción política y social, de juego de conectividad social, sin que, en lo esencial se alteren las estructuras y formas de explotación y reproducción social. En otras palabras, a pesar de los discursos que proliferan en la llamada Sociedad de la Información, la práctica creativa de concatenación de cuerpos y signos, de economía de signos y espacios, la puesta en escena y la reapropiación social de la ciudad, de sus imaginarios y formas culturales de representación, no son nuevas ni originales en las formas y contenidos de la planeación social. Por ello, es necesario problematizar la economía política y la cultura de innovación social asociada a las nuevas tecnologías y la revolución digital. Lo cual, a nuestro modo de ver, remite a la praxis y a la dimensión instituyente que tiene la imaginación y los imaginarios, en la estela de las preocupaciones de Cornelius Castoriadis (1998), poniendo de manifiesto el vínculo entre la imaginación y a la experiencia, del sujeto político y las clases subalternas en el EPO. Todos estos elementos son relevantes para comprender la tecnopolítica contemporánea, donde es 
preciso politizar, críticamente, la generación social de la comunicación y la cultura en una época de creciente disgregación y mercantilización del universo simbólico por las lógicas de mercificación ${ }^{10}$ de la innovación tecnológica y social.

Por lo mismo, es preciso repensar lo popular y la nueva economía moral de la multitud conectada. Hacerlo desde una lectura materialista puede, sin duda, contribuir a comprender mejor el alcance y la naturaleza de los nuevos movimientos de protesta que atraviesan el ciclo de crisis de acumulación que vive, hoy por hoy, el capitalismo en todo el mundo. De otro modo, la teoría y el estudio de la acción colectiva, no alumbrará sino la descripción de lo mismo en forma superficialmente distinta a base de la repetición positivista del acontecer como relato de las máquinas de sujeción que abundan en lo ya vivido, como ilustrara Guy Debord, con el desarrollo de la sociedad de consumo y las fábricas de sueño del Capital.

${ }^{10}$ Marx en El Capital, utiliza el término mercificación para hacer alusión, dentro de la temática de la fetichización da cultura, al impulso en ocasiones no intencionado o consciente que empuja a los individuos a saciar su instinto derrochador y consumista. 


\section{Referencias bibliográficas}

APC (Asociación para el Progreso de las Comunicaciones) (2006): Carta sobre derechos en Internet. Disponible en: https://www.apc.org/es/pubs/carta-de-apc-sobre-derechos-eninternet-descargar

BALIBAR, E. (2004): Derecho de ciudad. Cultura y política en democracia. Buenos Aires: Editorial Nueva Visión.

BISKY, L. (1982): Crítica de la teoría burguesa de la comunicación de masas. Madrid: Ediciones de la Torre.

BLANCHARD, D. (2007): Crisis de palabras. Notas a partir de Cornelius Castoriadis y Guy Debord. Madrid: Acuarelas \& Machado.

BLONDEAU, O., WHITEFORD, N. D., VERCELlONE, C., KYROU, A., CORSANI, A., RULLANI, E., MOULIER BOUTANG, Y. y LAZZARATO, M. (2004): Capitalismo cognitivo, propiedad intelectual y creación colectiva. Madrid: Traficantes de Sueños.

CASTEL, R. (2006): La sociología y la respuesta a la demanda social. En LAHIRE, B. (Ed.): ¿Para qué sirve la sociología? Buenos Aires: Siglo XXI Editores.

CASTORIADIS, C. (1998): Hecho y por hacer. Pensar la imaginación. Buenos Aires: EUDEBA.

DEAN, J. (2017): Multitudes y Partido. Pamplona: Katakrak Liburuak.

ECHEVERRÍA, B. (Comp.) (1994): Modernidad, mestizaje cultural y ethos barroco. México: UNAM/El Equilibrista.

GRAU, E. y IBARRA, P. (Coords.) (2004): La red en la calle. ¿Cambios en la cultura de movilización? Barcelona: Icaria.

HERNÁNDEZ, M. D., MARTÍN, P., y VILLASANTE, T. R. (2002): Estilos y coherencias en las metodologías participativas. En VILLASANTE, T. y GARRIDO, F. J.: Metodologías y 
presupuestos participativos. Construyendo ciudadanía/ 3. Madrid: CIMAS-IEPALA, pp. 1742.

HERRERA, J. (2007): O nome do riso. Breve tratado sobre arte e dignidade. Porto Alegre: Bernúncia Editora.

IBÁÑEZ, J. (1994): El regreso del sujeto: la investigación social de segundo orden. Madrid: Siglo XXI.

INNERARITY, D. (2009): La sociedad de la innovación. Notas para una teoría de la innovación social. En: INNERARITY, D. y GURRUTXAGA A.: ¿Cómo es una sociedad innovadora? Zamudio: Innobasque, pp.18-38.

KLUGE, A. y NEGT, O. (1993): Public Sphere and Experience: Toward an Analysis of the Bourgeois and Proletarian Public Sphere. USA: University of Minnesota Press

LACLAU, E. y MOUFFE, C. (2004): Hegemonía y estrategia socialista. Hacia una radicalización de la democracia. Buenos Aires: FCE.

LUTTWAK, E. N. (2000): Turbocapitalismo quiénes ganan y quiénes pierden en la globalización. Barcelona: Crítica.

MARTÍN, J. (1987): De los medios a las mediaciones. México: Gustavo Gili.

MARTÍN, M. (1977): La mediación social. Madrid: Akal.

MATTONI, A. y TRERÉ, E. (2016): Media Practices, mediation processes and Mediatization in the Study of Social Movements. Communication Theory, 24 (3), pp. 252271.

MODONESI, M. (2016): El principio antagonista. Marxismo y acción política. México: ITACA/UNAM.

MOROZOV, E. (2014): El nuevo mundo después de Snowden. [online] EL PAÍS. Disponible en: https://elpais.com/elpais/2014/o2/10/opinion/1392042566_270159.html 
NEGRI, A., y HARDT, M. (2000): Empire. London: Harvard University Press.

NEGT, O. (2007): L'espace public oppositionnel. Paris: Editions Payot.

POSTONE, M. (2006): Tiempo, trabajo y dominación social. Una reinterpretación de la teoría crítica de Marx. Barcelona: Marcial Pons.

RANCIÈRE, J. (2010): Las democracias contra la democracia. En AGAMBEN, G., BENSAID, D., ROSS, K., RANCIERE, J., NANCY, J., ZIZEK, S., WENDY, B. y BADIOU, A.: Democracia, ¿̇en qué estado? Buenos Aires: Prometeo.

RAUNIG, G. (2008): Mil máquinas. Breve filosofía de la máquina como movimiento social. Madrid: Traficantes de Sueños.

REGUILlO, R. (2017): Paisajes insurrectos. Jóvenes, redes y revueltas en el otoño civilizatorio. Madrid: NED EDICIONES.

RUEDA, R. (2006): Apropiación social de las tecnologías de la información: ciberciudadanías emergentes. Tecnología y Comunicación Educativas, No. 41, pp. 19-32.

SIERRA, F. (1999): Elementos de Teoría de la Información. Sevilla: Ediciones MAD.

(Coord.) (2016): Capitalismo Cognitivo y Economía Social del Conocimiento. Quito: CIESPAL.

(Ed.) (2018): Teoría del Valor, Comunicación y Territorio. Madrid: Akal.

SIERRA, F. y Montero, D. (Eds.) (2016): Videoactivismo y movimientos sociales. Barcelona: Gedisa.

SMYTHE, D. (1983): Las comunicaciones: "Agujero negro" del marxismo occidental. En RICHERI, G. (Comp.): La televisión entre servicio público y negocio. Gustavo Gili: Barcelona. 
THOMPSON, E. P. (1995): Costumbres en común. Barcelona: Crítica. (2002): Obra esencial. Barcelona: Crítica.

TORET, J. (Coord.) (2013): Tecnopolítica: la potencia de las multitudes conectadas. El sistema red 15M, un nuevo paradigma de la política distribuida. IN3 Working Paper Series, UOC Barcelona.

TREMBLAY, M. A. (1982): The Key Informant Technique: a Non-ethnographic Application. En BURGESS, R.G. (Ed.): Field Research: a Sourcebook and Field Manual. London: Routledge, Taylor \& Francis Group, pp. 151-163.

ZIZEK, S. (2006): Visión de paralaje. México: Fondo de Cultura Económica.

ZUBERO, I. (2004): Conocer para hacer: la tarea cultural de los movimientos sociales. En MARI-SÁEZ, V. M. (Coord): La red es de todos: cuando los movimientos sociales se apropian de la red. Madrid: Editorial Popular, pp. 59-75. 